\title{
Prehistoric fishing on Rapa Island
}

\author{
Yolanda Vogel \\ Department of Anthropology, University of Otago, Dunedin, New Zealand, \\ bones.stones@gmail.com \\ Atholl Anderson \\ Department of Archaeology and Natural History, The Australian National University
}

\section{Introduction}

This chapter presents the results of analysing fish-bone assemblages from Rapa, while Chapter 9 will discuss some points of interpretation. The material was recovered from a number of rockshelter sites around Rapa (see Chapter 3, Figure 3.1 for site locations). Most of the fish bone comes from the Tangarutu rockshelter, with another large assemblage from the Akatanui 3 rockshelter. Four other rockshelters (Akatanui 1, Angairao C, Angairao E and Noogoriki) provided only small amounts of fish bone. The material was dry sieved in the field using $3 \mathrm{~mm}$ sieves, and bulk samples were also retained at most sites. Primary sorting occurred in The Australian National University archaeological laboratory (Department of Archaeology and Natural History), where bulk samples were sieved to $2 \mathrm{~mm}$. Residues were retained. The fishbone component was sent to the Otago Archaeology Laboratory (OAL), in the Anthropology Department, University of Otago, for further analysis by Vogel.

\section{Methods}

The fish bone is in a very good state of preservation. It was identified using the OAL Pacific fish-bone reference collection, which contains 108 specimens in 33 families and 49 genera, with seven specimens having no information below family level (see Appendix A for the full list).

Many studies of prehistoric Pacific fishing practices have relied on the protocol devised by Anderson (1973, 1979) and Leach $(1979,1986)$, which involved identification of five paired mouth bones (dentary, premaxilla, articular, maxilla and quadrate), plus various 'special' bones. However, recent work in Pacific fish-bone analysis at the OAL and other laboratories has shown that different identification and quantification methods significantly influence measures of relative abundance and the number of taxa represented, thereby affecting interpretations (Weisler 1993; Walter 1998; Vogel 2005). During the rebuilding of the OAL Pacific fish-bone collection in the early 1990s, it was decided to include a wider range of elements beyond the five paired mouth bones and 'special' bones, in order to address a greater range of issues in 
Pacific ichthyoarchaeology (Walter et al. 1996). Currently, the collection allows for the routine identification of 17 elements from the cranium, pectoral girdle and pelvic girdle, plus otoliths and some 'special' elements, and it is these that were used in this study.

Identification of the fish bone involved two steps - to element and to taxon. As much as possible of the assemblage was identified to element, using reference specimens and diagrams (e.g. Cannon 1987; Wheeler and Jones 1989; Rojo 1991). The remaining material consisted of fragments with no landmark features, plus material that was unable to be identified to element at this stage. Seventeen elements, plus dorsal spines for Acanthuridae and Balistidae, dermal spines for Diodontidae, teeth and vertebra for Elasmobranchii, and fourth epibranchials for Scaridae, were then identified to family (see Table 7.1). Where a family match did not exist in the OAL reference collection, the element was recorded as Not in Collection (NIC), followed by a number to distinguish between elements obviously from different families. Otoliths were absent from the assemblages. It is possible they did not survive, but this does not seem likely, given that otoliths have been shown to survive when other elements have not (Weisler 1993; Weisler et al. 1998), and given the overall excellent preservation of the fish remains. Another possibility, given the overall very small size of the fish represented in the assemblages, is that even with the use of $3 \mathrm{~mm}$ sieves, the otoliths were so small they were not retained. Bulk sample residues were retained, and microscopic investigation of these in the future may reveal the presence of otoliths.

Considerable debate exists within archaeology about the best method of quantification (Grayson 1984), and Pacific ichthyoarchaeology is no exception to this (Butler 1988; Walter 1998). Issues surrounding the use of NISP (Number of Identified Specimens) pertain to the fragmentation level of the material analysed, differing numbers of elements identified for different taxa, and taxa identified by 'special' bones, of which there are multiple numbers per individual. The main issue with the use of MNI (Minimum Number of Individuals) has to do with the units of aggregation used. In order to alleviate some of the problems inherent in the different quantification methods, both NISP and MNI are reported here, along with the raw data on which they are based, thus providing a much fuller account of the archaeological assemblage than would be provided by MNI counts alone. The use of the two quantification methods also allows for greater comparability between the Rapan assemblages and those from other islands in the Pacific, as many reports contain results using only one or the other method.

Table 7.1. Elements identified to taxonomic level.

\begin{tabular}{ll}
\hline Elements & \\
\hline Vomer & Epihyal \\
Parasphenoid & Inferior pharyngeal cluster \\
Post temporal & Superior pharyngeal cluster \\
Articular & Cleithrum \\
Dentary & Scapula \\
Maxilla & Palatine \\
Premaxilla & Dorsal spine (Acanthuridae and Balistidae only) \\
Quadrate & Dermal spine (Diodontidae only) \\
Opercular & Tooth (Elasmobranchii only) \\
Preopercular & Vertebra (Elasmobranchii only) \\
Hyomandibular & 4th epibranchial (Scaridae only) \\
Ceratohyal & \\
\hline
\end{tabular}


NISP is given for all material, whereas MNIs were calculated using the 17 elements targeted for family-level identification (see Tables 7.2, 7.3). MNI was calculated by taking the most frequent sided element (or straight element count in the case of unpaired bones) for each family. No attempts were made to account for size matching.

\section{Results}

Twenty-one families, one subclass (Elasmobranchii) and one order (Anguilliformes) were identified in the assemblage, while at least six additional families represented in the archaeological record were not in the OAL collection (elements designated as NIC). This latter number was calculated based on the presence of six distinctive sets of hyomandibular bones throughout the assemblages. The NIC material has been excluded from the remainder of this paper because MNIs cannot be generated accurately; full details for the elements represented in this category are given in Appendix A.

The top-ranked taxa are Scaridae (parrotfish), Muraenidae (moray eels), Chaetodontidae (butterflyfish), Labridae (wrasses), Serranidae (grouper), Pomacentridae (damselfish) and Congridae (conger eels). The presence of Muraenidae, Congridae, Chaetodontidae and Pomacentridae in the highest-ranked taxa is somewhat anomalous, and will be discussed further later. The remaining three taxa, Scaridae, Serranidae and Labridae, commonly rank highly in tropical East Polynesian fish-bone assemblages. The following families were represented only in small numbers: Lethrinidae, Acanthuridae, Mullidae, cf. Aulostomidae, Belonidae, Exocoetidae, Holocentridae, Kyphosidae, Mugilidae, Siganidae, Bothidae, Carangidae, Diodontidae, Elasmobranchii, Monacanthidae and Anguilliformes, and a number of specimens not in the reference collection. The results for each site are presented below.

\section{Tangarutu Cave}

The material from Tangarutu forms the largest assemblage, with a total of 14,419 bones, and it is made up of material from a number of sampling stations within the site (Appendix A). Each of these will be considered as separate units, as the stratigraphic association between them, although broadly apparent (Chapter 3), is uncertain in detail. The bulk of the material comes from the E1 and E2 contiguous units, considered here as a single unit, and the R1 unit.

\section{Excavation E1/E2}

This was an excavation of approximately $1.5 \mathrm{~m}^{2}$, although, as explained in Chapter 3, only part of the E2 area was taken down to natural. The stratigraphy was divided into three levels (I (oldest) to III, details in Chapter 3) and results of bone identification are grouped into these and shown in Figures 7.1-7.3. A total of 21 families were identified to taxa, although the exact number and composition varies between levels. The assemblage from this excavation consists of 11,417 pieces of fish bone.

In the lowest level, the top five taxa, all representing more than $5 \%$ of the assemblage each, make up $87 \%$ of the assemblage. The remaining 11 taxa in this layer all comprise less than $2 \%$ of the assemblage each. Figure 7.1 shows a clear dominance by Scaridae, comprising $40 \%$ of the assemblage. The other taxa in the top five, in order of abundance, are Muraenidae, Labridae, Chaetodontidae and Serranidae.

The pattern seen in Level I changes in Level II (Figure 7.2). Scaridae drops to $17 \%$ of the assemblage, and Muraenidae becomes the top-ranking taxon. Chaetodontidae also increases to $16 \%$, Labridae increases slightly to $12 \%$, while a second eel family, Congridae, takes the place of Serranidae as fifth-ranked taxon. Serranidae drops to sixth in terms of rank order, representing 
Table 7.2. MNI for all sites.

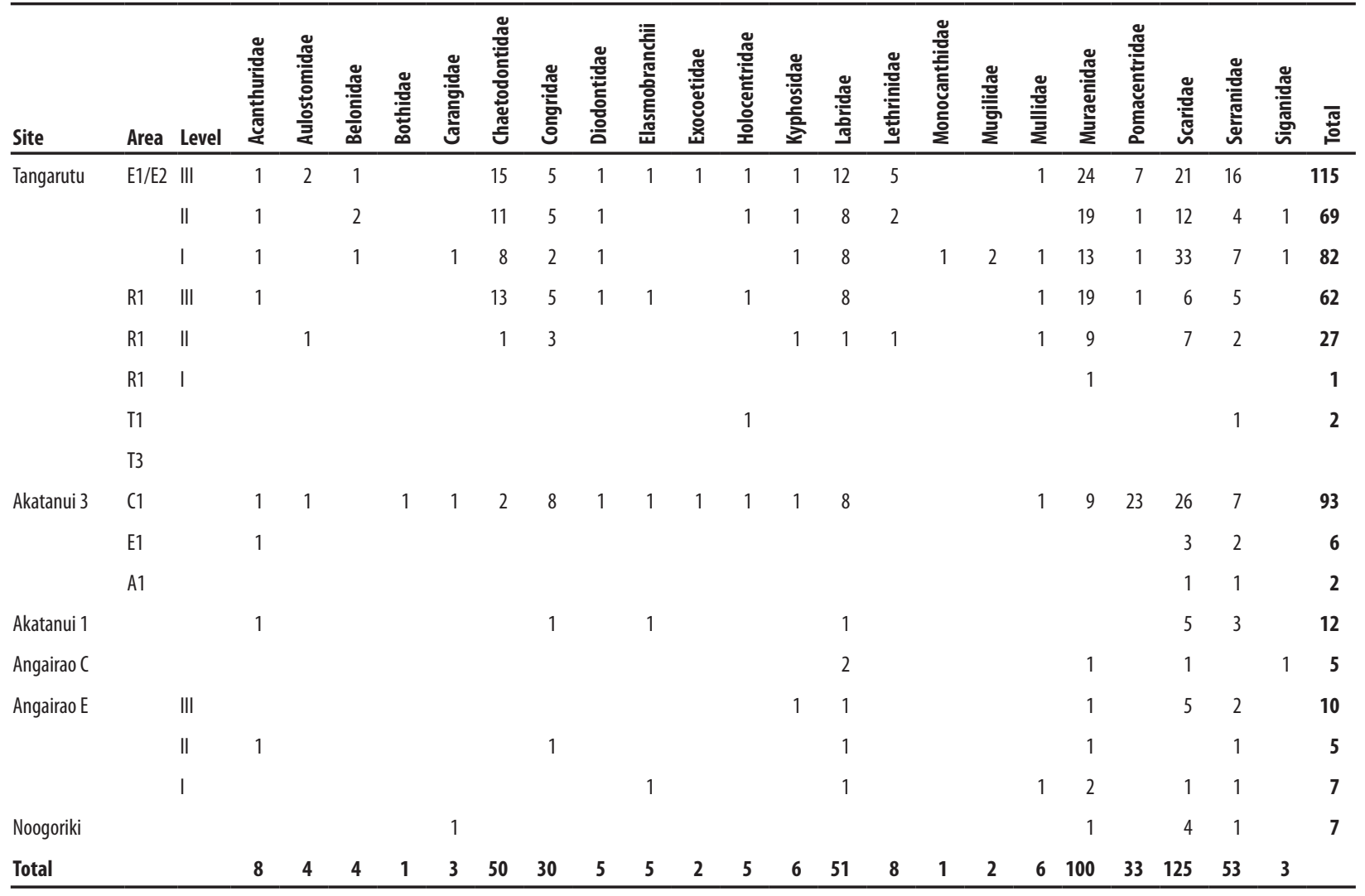

Table 7.3. NISP for all elements identified to taxa.

\begin{tabular}{|c|c|c|c|c|c|c|c|c|c|c|c|c|c|c|c|c|c|c|c|c|c|c|c|c|c|}
\hline Site & Area & Level & 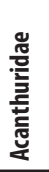 & 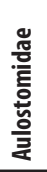 & 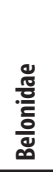 & 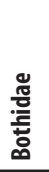 & 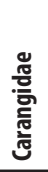 & 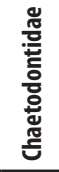 & $\begin{array}{l}\text { 응 } \\
\text { 흫 } \\
\text { 잉 }\end{array}$ & 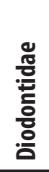 & 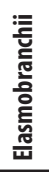 & 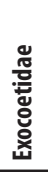 & 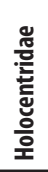 & 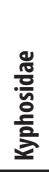 & 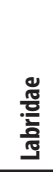 & 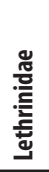 & 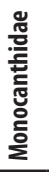 & 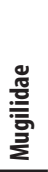 & 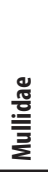 & 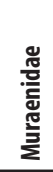 & 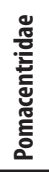 & 冚 & 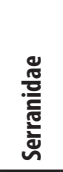 & 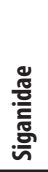 & 厄ँّ \\
\hline \multirow[t]{8}{*}{ Tangarutu } & $\mathrm{E} 1 / \mathrm{E} 2$ & III & 6 & 7 & 4 & & & 56 & 28 & 4 & 6 & 3 & 6 & 2 & 52 & 11 & & & 5 & 97 & 15 & 180 & 230 & & 712 \\
\hline & & $\|$ & 1 & & 3 & & & 43 & 22 & 1 & & & 1 & 4 & 56 & 3 & & & & 67 & 3 & 75 & 57 & 1 & 337 \\
\hline & & I & 6 & & 5 & & 1 & 26 & 8 & 3 & & & & 1 & 27 & & 1 & 2 & 2 & 52 & 4 & 303 & 57 & 7 & 505 \\
\hline & $\mathrm{R} 1$ & III & 1 & & & & & 24 & 31 & 2 & 1 & & 1 & & 42 & & & & 3 & 56 & 2 & 73 & 55 & & 291 \\
\hline & $\mathrm{R} 1$ & $\|$ & & 1 & & & & 2 & 6 & & & & & 1 & 5 & 1 & & & 2 & 26 & & 32 & 13 & & 89 \\
\hline & $\mathrm{R} 1$ & 1 & & & & & & & & & & & & & & & & & & 1 & & & & & 1 \\
\hline & $\mathrm{T} 1$ & & & & & & & & & & & & 1 & & & & & & & & & & 1 & & 2 \\
\hline & $\mathrm{T} 3$ & & & & & & & & & & & & & & & & & & & & & & & & 0 \\
\hline \multirow[t]{3}{*}{ Akatanui 3} & C1 & & 1 & 1 & & 2 & 2 & 5 & 33 & 1 & 13 & 2 & 2 & 3 & 31 & & & & 4 & 31 & 75 & 166 & 75 & & 447 \\
\hline & E1 & & 2 & & & & & & & & & & & & & & & & & & & 15 & 3 & & 20 \\
\hline & $\mathrm{A} 1$ & & & & & & & & & & & & & & & & & & & & & 4 & 2 & & 6 \\
\hline Akatanui 1 & & & 1 & & & & & & 1 & & 2 & & & & 1 & & & & & & & 28 & 14 & & 47 \\
\hline Angairao C & & & & & & & & & & & & & & & 2 & & & & & 2 & & 1 & & 1 & 6 \\
\hline \multirow[t]{3}{*}{ Angairao $\mathrm{E}$} & & III & & & & & & & & & & & & 1 & 1 & & & & & 3 & & 19 & 5 & & 29 \\
\hline & & $\|$ & 1 & & & & & & 1 & & & & & & 1 & & & & & 2 & & & 1 & & 6 \\
\hline & & I & & & & & & & & & 1 & & & & 1 & & & & 1 & 3 & & 5 & 1 & & 12 \\
\hline Noogoriki & & & & & & & 1 & & & & & & & & & & & & & 1 & & 6 & 4 & & 12 \\
\hline Total & & & 19 & 9 & 12 & 2 & 4 & 156 & 130 & 11 & 23 & 5 & 11 & 12 & 219 & 15 & 1 & 2 & 17 & 341 & 99 & 907 & 518 & 9 & \\
\hline
\end{tabular}


$6 \%$ of the assemblage. A further eight taxa comprise $3 \%$ or less of the assemblage each.

There are also notable changes in rank order in Level III (Figure 7.3). Serranidae increases to $14 \%$ of the assemblage, and is ranked third. Pomacentridae now represents $6 \%$ of the assemblage, up from $1 \%$. Muraenidae remains the top-ranked taxon, but falls in terms of percentage of the assemblage.
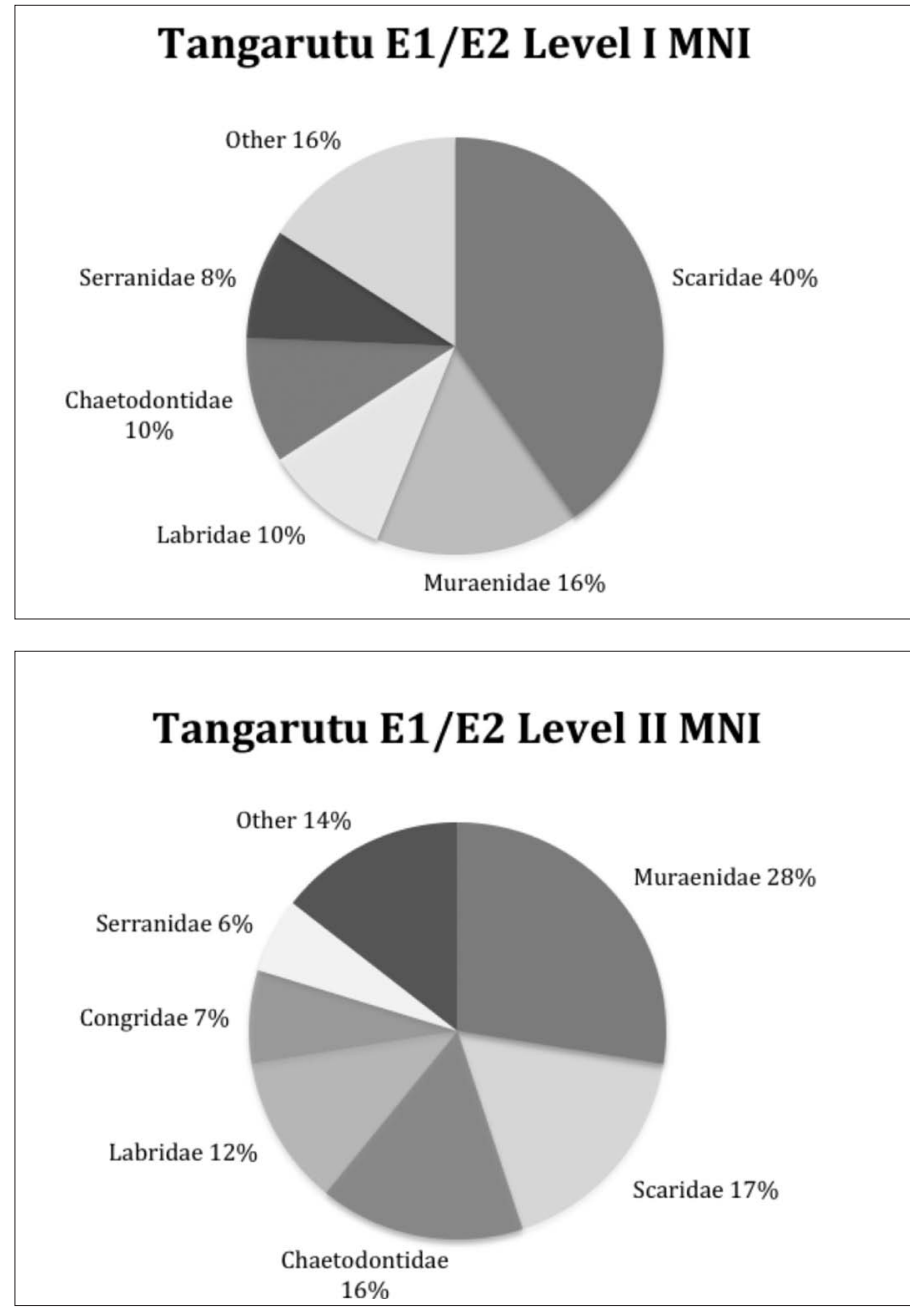

\section{Tangarutu E1/E2 Level III MNI}

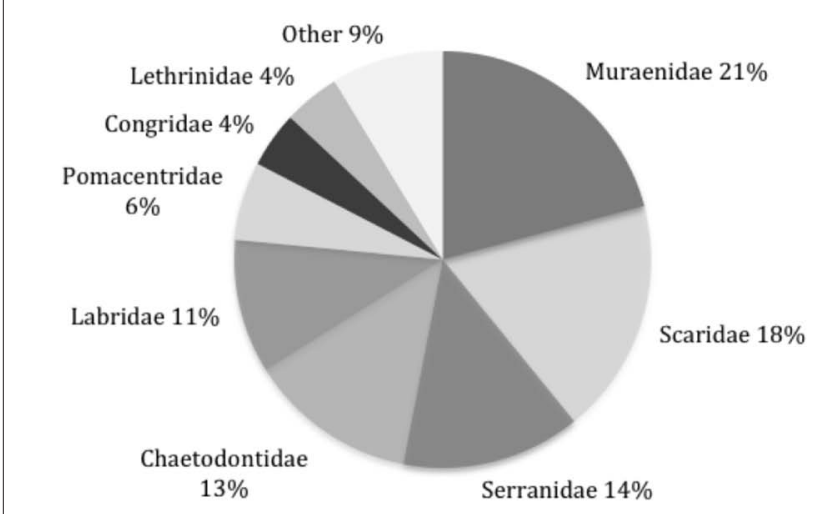

Figure 7.1. Relative abundance (MNI) of taxa for Tangarutu E1/E2 Level I.

Figure 7.2. Relative abundance (MNI) of taxa for Tangarutu E1/E2 Level II.

Figure 7.3. Relative abundance (MNI) of taxa for Tangarutu E1/E2 Level III. 


\section{Excavation R1}

This material comes from a $1 \mathrm{~m}^{2}$ square excavation and the assemblage consists of 2845 pieces of fish bone, representing 14 families able to be identified to taxa. Overall, the top-ranking taxa are the same as those seen in the E1/E2 area, although there are some differences in rank order (Figures 7.4-7.5).

The lowest level of the R1 area contained very little fish bone (NISP=22), with only one bone able to be identified to taxon. This belonged to the family Muraenidae. In Level II, the top four taxa make up $78 \%$ of the assemblage, with a further six taxa contributing the remaining $22 \%$. Taxa in this latter group all have an MNI of one. Figure 7.4 shows a dominance by Muraenidae, comprising 33\% of the assemblage, followed by Scaridae, Congridae and Serranidae in order of abundance. Together, Muraenidae and Scaridae make up more than half the Level II assemblage.

Level III shows a dramatic change in the pattern from that in Level II (Figure 7.5). Muraenidae remains the top-ranking taxon, but there is a considerable increase in the number of Chaetodontidae represented, increasing to $21 \%$ of the assemblage (Chaetodontidae is present in Level II, but with an MNI of only one, falls into the category of 'other'). Concurrently, there is a marked decrease in Scaridae, now representing only $10 \%$ of the assemblage. Labridae numbers also increase in Level III, contributing 13\%, while Congridae falls slightly in terms of percentage and Serranidae remains stable. Six taxa, each with an MNI of one, make up the remaining $10 \%$ of the assemblage.
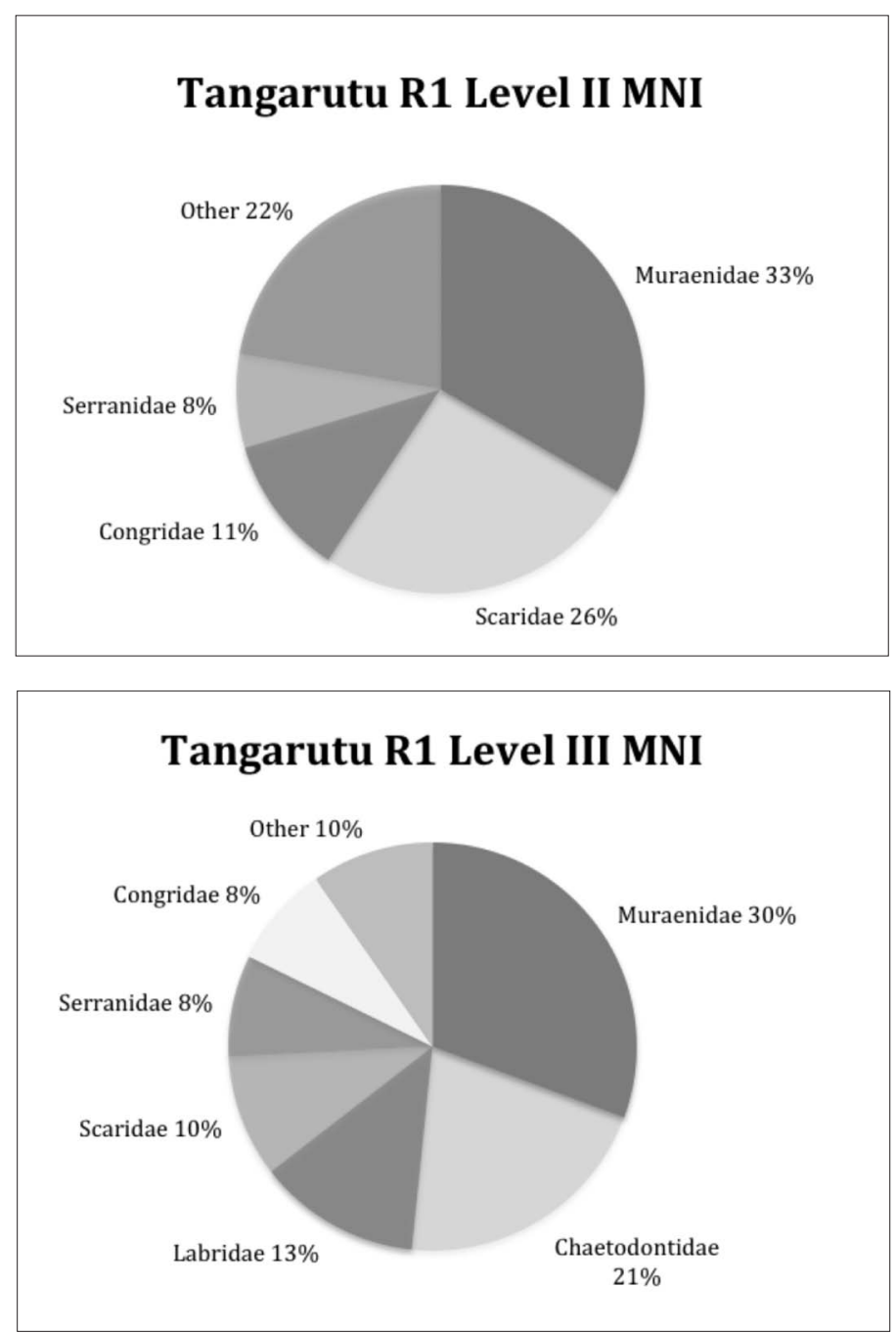

Figure 7.4. Relative abundance (MNI) of taxa for Tangarutu R1 Level II.

Figure 7.5. Relative abundance (MNI) of taxa for Tangarutu R1 Level III. 
In light of the results for the R1 area, it was decided to re-examine the E1/E2 data for Level II, to see whether the decrease in Scaridae and increase in Chaetodontidae could be pinpointed more accurately. This revealed that Scaridae is still the dominant taxon at the base of Level II (Figure 7.6), falling to fourth rank in the middle of Level II, where it comprises $13 \%$ of the assemblage (Figure 7.7), and falling further to fifth rank and only $6 \%$ of the assemblage at the top of Level II (Figure 7.8). Chaetodontidae represents only $7 \%$ of the assemblage at the base of Level II, although it ranks third, but it increases significantly in the middle of Level II to become the dominant taxa. At the top of Level II, Chaetodontidae and Muraenidae rank first equal. Thus, the initial analysis of Level II masks some quite significant changes in the assemblage, and the increasing importance of Chaetodontidae.

The E1/E2 data for Level III were also reanalysed, to see whether the changes in that level were also more abrupt than the initial results suggest, particularly in terms of the Scaridae, which clearly increase in numbers again from the low seen at the top of Level II. The data for Level III were split into two subsets representing spits $1-4$ and spits $5-8$. The decision about where to make the split was chiefly based on the appearance of fish hooks in this level (see below). Muraenidae maintains its dominance in the bottom half of Level III (Figure 7.9), but Chaetodontidae numbers drop off considerably, falling to third rank and only $12 \%$ of the assemblage. In contrast, Serranidae numbers increase significantly, to $17 \%$. Scaridae increases to $12 \%$ of the assemblage, placing it fourth equal with Chaetodontidae, while Labridae and Congridae both drop in numbers and rank.

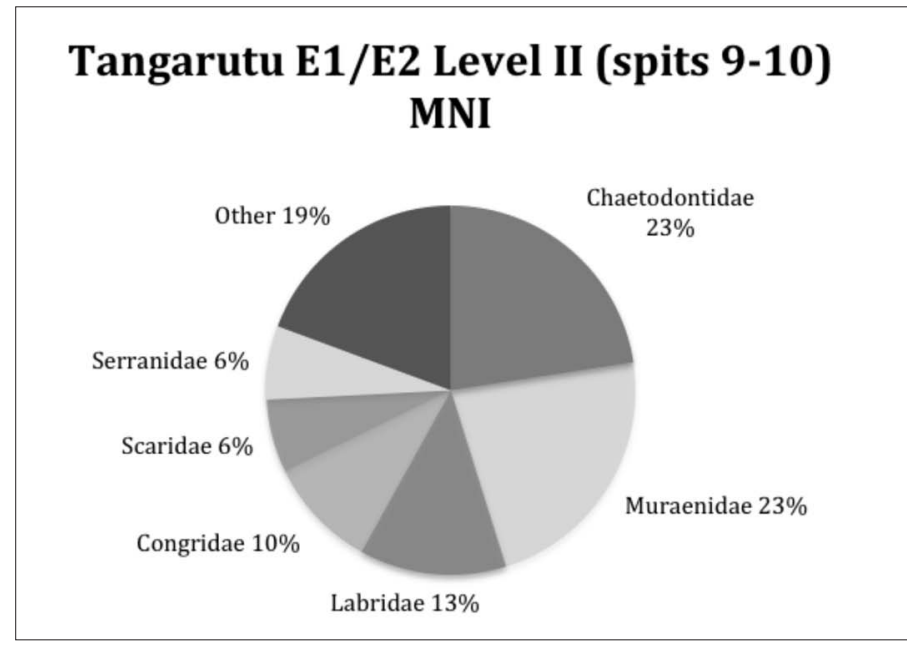

\section{Tangarutu E1/E2 Level II (spits 11-12) MNI}

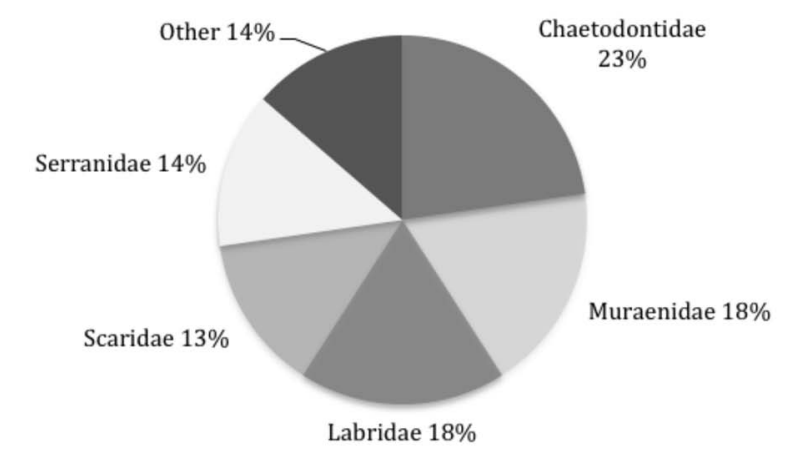

Figure 7.6. Relative abundance (MNI) of taxa for Tangarutu E1/E2 Level II spits 9-10.
Figure 7.7. Relative abundance (MNI) of taxa for Tangarutu E1/E2 Level II spits $11-12$. 


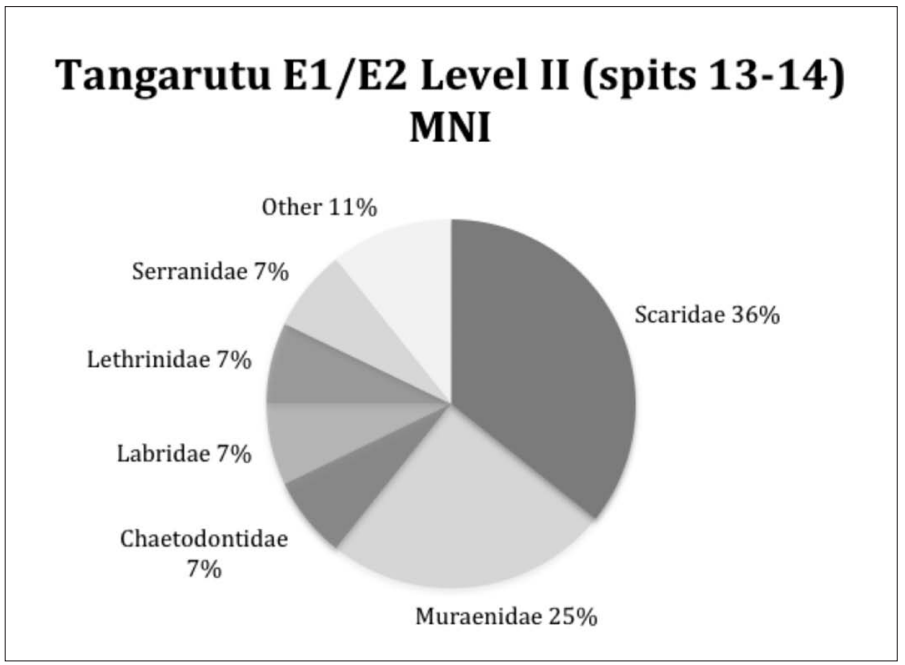

Figure 7.8. Relative abundance (MNI) of taxa for Tangarutu E1/E2 Level II spits 13-14.

In the top half of Level III, Scaridae becomes the dominant taxon once again, representing $20 \%$ of the assemblage (Figure 7.10). Muraenidae numbers drop, along with its fall to second rank, as does Serranidae, slipping back to fourth rank and $13 \%$ of the assemblage. Chaetodontidae remains fairly stable. It is in this upper part of Level III that Pomacentridae increases in numbers also, now representing $8 \%$ of the assemblage. As with Level II, the initial analysis of Level III masked some interesting changes in terms of taxa representation and rank order abundance.

\section{Additional Tangarutu assemblages}

Tangarutu T1 and T3 are both very small assemblages resulting from facing of sections (i.e. cutting straight sections down exposed faces to inspect stratigraphy and content). The T1 area yielded 49 pieces of fish bone, of which two could be identified to taxa, while another two belonged to a taxon not represented in the OAL collection. This resulted in an MNI of one for Serranidae and Holocentridae, and an MNI of two for the unknown taxon. The T3 area yielded 108 pieces of fish bone, of which none were identifiable to taxa. The majority of this assemblage was made up of scales, with a NISP of 72 .

\section{Akatanui shelters}

The Akatanui Bay assemblages come from two separate rockshelters: Akatanui 1 and Akatanui 3 (Appendix A). The Akatanui 3 excavations resulted in material from three areas: $\mathrm{C} 1$, which was an excavation of $2 \mathrm{~m}^{2}$, and test pits at $\mathrm{E} 1$ and $\mathrm{A} 1$.

\section{Akatanui $3 \mathrm{C} 1$ excavation}

This area yielded the greatest amount of fish bone for this shelter, with a total of 2490 pieces recovered. The results of the taxonomic identification, based on MNI, are shown in Figure 7.11. The taxa exploited are essentially the same as those at Tangarutu, but the rank ordering is quite different. Scaridae and Pomacentridae together make up more than half of the assemblage. While both eel families are still represented in the top six taxa, their contribution is far less than at Tangarutu, particularly in the case of Muraenidae. Interestingly, Chaetodontidae, one of the top-ranking taxa at Tangarutu, makes very little contribution to this assemblage.

\section{Additional Akatanui assemblages}

Akatanui E1 and A1 are both very small assemblages. The E1 material consists of 122 pieces of bone. Three taxa were identified: Scaridae $(\mathrm{MNI}=3)$, Serranidae $(\mathrm{MNI}=2)$ and Acanthuridae $(\mathrm{MNI}=1)$. The $\mathrm{A} 1$ assemblage contains only nine pieces of bone, but six of these were identified 


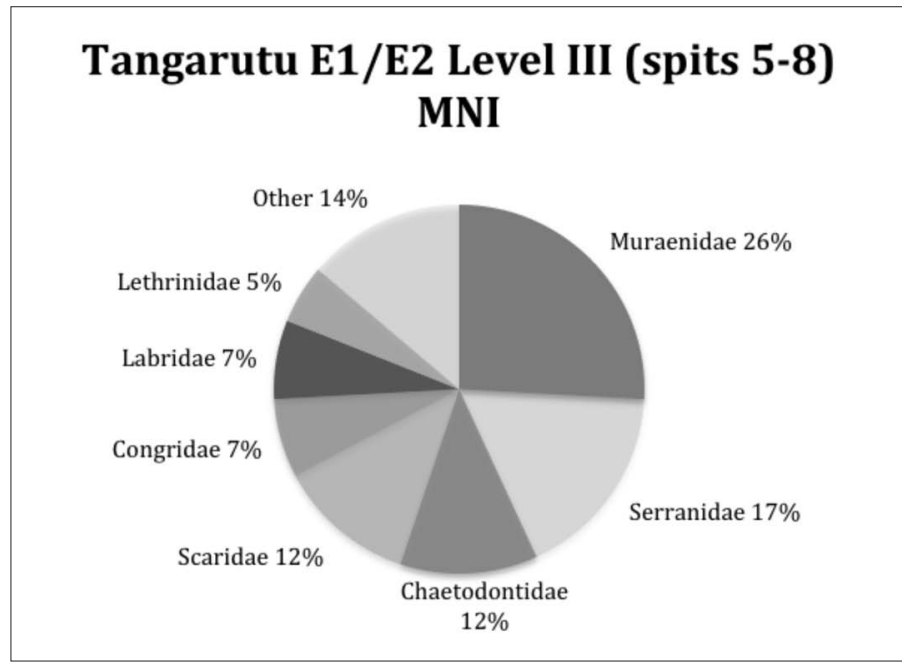

Tangarutu E1/E2 Level III (spits 1-4) MNI
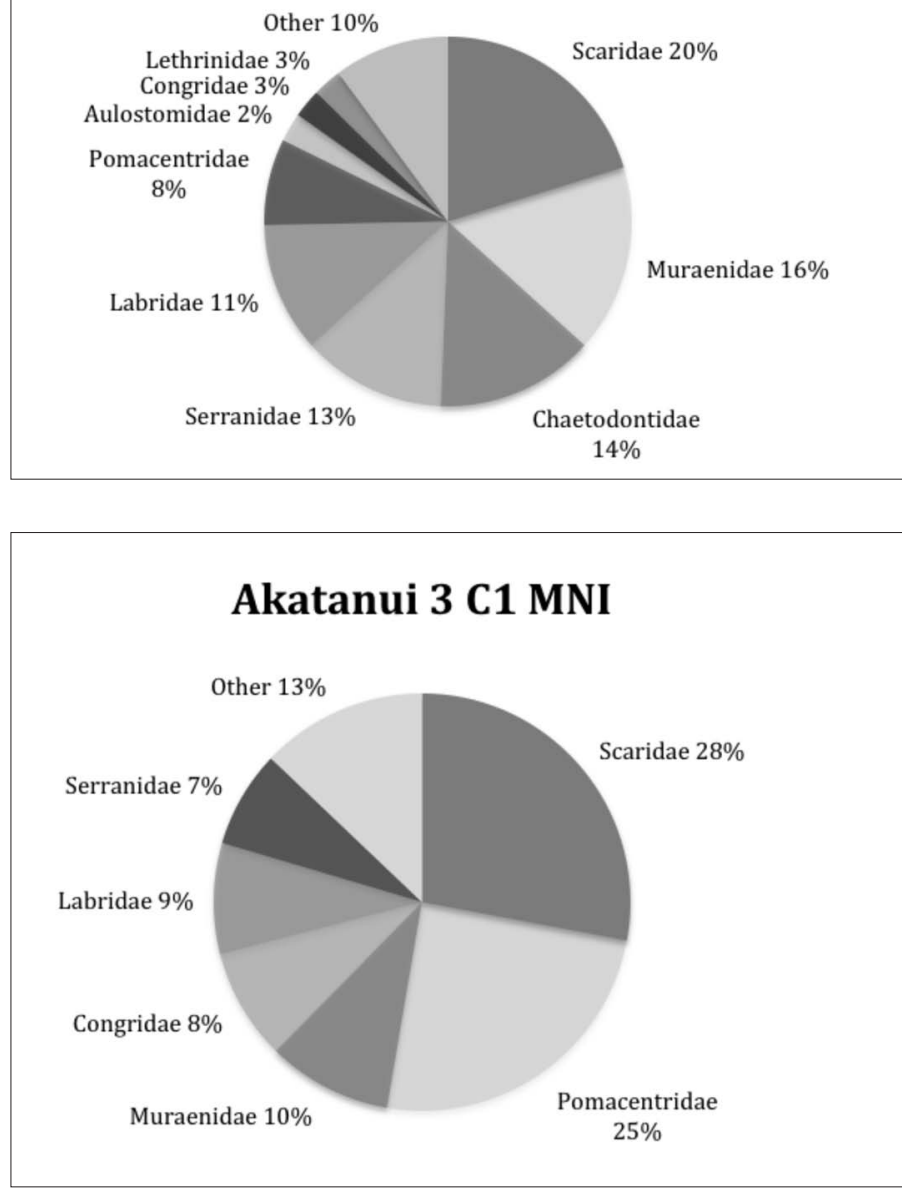

Figure 7.9. Relative abundance (MNI) of taxa for Tangarutu E1/E2 Level III spits 5-8.

Figure 7.10. Relative abundance (MNI) of taxa for Tangarutu E1/E2 Level III spits 1-4.

Figure 7.11. Relative abundance (MNI) of taxa for Akatanui 3 C1. 
to taxa, resulting in an MNI of one each for Scaridae and Serranidae. Akatanui 1 yielded a very small assemblage, consisting of 338 pieces of fish bone. Six taxa were identified: Scaridae $(\mathrm{MNI}=5)$, Serranidae $(\mathrm{MNI}=3)$, Acanthuridae $(\mathrm{MNI}=1)$, Congridae $(\mathrm{MNI}=1)$, Elasmobranchii $(\mathrm{MNI}=1)$ and Labridae $(\mathrm{MNI}=1)$.

\section{Angairao Bay shelters}

The material from Angairao Bay comes from three provenances (Appendix A). The most productive of these was the excavation at Angairao E.

\section{Angairao E excavation}

This was a $1.2 \mathrm{~m} \times 0.6 \mathrm{~m}$ excavation down to $70 \mathrm{~cm}$ and then $0.5 \mathrm{~m} \times 0.6 \mathrm{~m}$ below that (Chapter 3). In the top $70 \mathrm{~cm}$, there were remains of an oven, but with no associated midden. The midden was in an underlying unit ('Oven 2'), at 70-165 cm depth, which was divided into three levels (Chapter 5) for bone analysis.

The Angairao E assemblage yielded a total of 269 pieces of fish bone. While nine taxa were identified in the assemblage, only three are present in all levels: Serranidae, Labridae and Muraenidae. Scaridae, however, has the highest overall MNI. The MNI and NISP by level can be seen in Tables 7.2 and 7.3.

\section{Additional Angairao assemblages}

The Angairao C assemblage consisted of 30 pieces of fish bone, from which four taxa were identified: Labridae $(\mathrm{MNI}=2)$, Scaridae $(\mathrm{MNI}=1)$, Muraenidae $(\mathrm{MNI}=1)$ and Siganidae (MNI=1). The Noogoriki assemblage, from the opposite side of Angairao Bay (Chapter 3), consisted of 27 pieces of fish bone, with four taxa able to be identified: Scaridae (MNI=4), Muraenidae (MNI=1), Serranidae $(\mathrm{MNI}=1)$ and Carangidae $(\mathrm{MNI}=1)$.

\section{Discussion}

The reconstruction of past fishing practices requires more than just archaeological faunal data. Information on local ecology, ethnographic accounts of fishing, and information on material culture relating to fishing (Walter and Weisler 2002) are also useful sources. Ethnographic information on fishing for Rapa is discussed in Chapters 2 and 9, and these data can be combined with analogies from other Pacific islands to provide a more rounded interpretation than afforded by the faunal data alone.

Fishing strategies can also be reconstructed to some extent by considering the preferred habitats and feeding behaviours of the taxa represented in the faunal assemblage (Butler 1994; Walter 1998; Allen et al. 2001; Weisler 2001). This method is not without its problems, as species within some families can inhabit different ecological zones (e.g. Serranidae). Using feeding behaviour to infer capture techniques is also problematic, because some taxa can be caught using a number of techniques, and feeding behaviour and capture techniques can also vary between species within a family. Nevertheless, such data can help to delimit the possibilities of fishing strategy.

Table 7.4 has been constructed by taking a broader view of tropical Polynesian ethnographic information on fishing techniques and ecological variation. Walter (1998) divides the marine exploitation zones into five categories (offshore pelagic, inshore pelagic, inshore benthic, reef edge and reef flat), and Allen et al. (2001) include lagoon as one of their zones. Rapa differs from many Pacific islands in that it has lagoon of any extent only in Ha'urei Harbour, while around the open sea perimeter there is almost no intertidally exposed fringing reef. In this respect, a better analogy in terms of marine environment may be provided by Easter Island. Rapa is 
surrounded by a gently sloping platform, on which coral communities grow in the sheltered bays, perhaps providing a zone similar to the reef flats of other islands. With this in mind, the marine zones have been broken into only three categories: inshore, benthic and pelagic.

Another factor likely to be important to reconstructions of past fishing behaviour is the dichotomy between the marine environment within the many bays and that outside the bays. The bays are noted as being relatively calm, although Haurei Harbour is often choppy and turbid, especially towards the head. The remaining coastline is characterised by steep cliffs and, frequently, rough waters. While there are areas of rocky shore outside the bays, the predominance of cliffs rising almost directly from the water's edge ensured fishing outside the bays was usually from a canoe.

Putting the information in Table 7.4 together with the results of fish-bone analysis, it is possible to draw some conclusions about the nature of fishing at the various sites around Rapa.

\section{Tangarutu}

Fishing from this site seems to have concentrated almost exclusively on the inshore zone. The few taxa that are associated more often with offshore zones rank very low, and they are probably best interpreted as opportunistic or unintentional catches of fish that came into the bay and

Table 7.4. The ecology of taxa identified in the Rapan assemblages and possible methods of capture.

\begin{tabular}{|c|c|c|c|c|}
\hline Family & Habitat/Zone & Activity & Feeding & Capture technique \\
\hline Acanthuridae & Inshore benthic, reef edge, reef flat & Diurnal & Herbivore & Netting, trapping, spearing, angling \\
\hline Aulostomidae & Outer reef, reef flat & & Piscivore & \\
\hline Belonidae & Inshore & & & Trolling \\
\hline Bothidae & Inshore & & & Netting \\
\hline Carangidae & Reef flat, passes, outer reef & Various & Piscivore & Angling, netting, spearing \\
\hline Chaetodontidae & Inshore & Diurnal & Invertebrates & Netting \\
\hline Congridae & Reef & Nocturnal & Carnivore & \\
\hline Diodontidae & Reef flat, outer reef & Nocturnal & Invertebrates & Angling, trapping, netting \\
\hline Elasmobranchii & Outer reef, pelagic & & $\begin{array}{l}\text { Omnivore/benthic } \\
\text { carnivore }\end{array}$ & Angling, spearing, netting \\
\hline Exocoetidae & Pelagic & Various & Omnivore & Netting \\
\hline Holocentridae & Reef flat, outer reef & Nocturnal & Invertebrates & Angling, netting \\
\hline Kyphosidae & Reef flat, outer reef & Diurnal & Herbivore & \\
\hline Labridae & Reef flat, outer reef & Diurnal & Invertebrates & Angling, netting, trapping \\
\hline Lethrinidae & Reef flat, outer reef & Nocturnal & Invertebrates & Angling, netting \\
\hline Monocanthidae & Inshore & & Omnivore & \\
\hline \multicolumn{5}{|l|}{ Mugilidae } \\
\hline Mullidae & Reef flat & & Omnivore & Netting, angling \\
\hline Muraenidae & Reef flat & Nocturnal & Carnivore & Spearing, poisoning, trapping, snaring, netting \\
\hline Pomacentridae & Inshore & Diurnal & Omnivore & Angling, netting, trapping \\
\hline Scaridae & Inshore & Diurnal & Herbivore & Netting, spearing, trapping \\
\hline Serranidae & Inshore & & Piscivore & Angling, netting, trapping, spearing, poison \\
\hline Siganidae & Inshore & & & Netting, trapping \\
\hline
\end{tabular}


closer to shore than usual. This pattern is fairly typical of Pacific marine exploitation systems (Anderson 1986:ix).

The oldest level in the E1/E2 area at Tangarutu shows a clear dominance of Scaridae, but this gives way to a dominance by Chaetodontidae and Muraenidae in the middle level and Muraenidae in the upper level. Interestingly, Scaridae numbers increase again in the upper level. While the presence of Muraenidae in the assemblage is not unusual in itself, these eels usually rank very low in terms of relative abundance at other sites throughout the Pacific.

Another interesting observation about this assemblage is the high incidence of Chaetodontidae, particularly in Level II. This represents the first positive identification of Chaetodontidae in an assemblage from the Pacific. This is probably related to the methodology used for identification. However, it cannot be assumed that Chaetodontidae has merely been overlooked in all other Pacific assemblages, nor that it would occur in such high numbers were it to be identified in other assemblages. Given the dominance by Muraenidae in much of the Tangarutu assemblage, it is safe to say that this assemblage differs considerably from many others in the region in terms of some of the favoured, or available, taxa, and the presence of Chaetodontidae is probably evidence of this.

Occupation at Tangarutu spanned about 500 years, and there is obvious change through time in the assemblage. The first of these changes is an apparent decrease in Scaridae. One possible explanation for this is simply differential survivability. Scaridae has some elements that are particularly robust, and thus has an increased likelihood of survival through time (Bilton 2001). In this scenario, numbers of identifiable elements for other taxa are fewer in older layers due to taphonomic factors, while Scaridae elements remain intact, but in younger layers greater survival of elements from other taxa reduces the proportional representation of Scaridae. When considering the percentage of unidentified fragments in each level, the amount for the oldest level is significantly higher than for the other layers $(32.5 \%$ in the oldest, versus $22 \%$ for the middle level and $18.5 \%$ for the youngest), which does lend weight to this argument, although no data were collected on the size of the fragments, so it might be only that the unidentified fragments in the lowest layer are more fragmented. If so, that was not obvious during excavation; indeed, the contrary seemed more apparent.

However, as the assemblage as a whole shows excellent preservation, it is unlikely that differential survivability has skewed the numbers in favour of Scaridae to any great extent, and therefore it cannot explain the marked change in abundance between the lowest and middle levels. Also, Labridae is subject to the same positive bias as Scaridae in terms of survivability (Bilton 2001), yet its relative abundance between the oldest and middle levels remains fairly constant. Another possible explanation is that the earliest occupants focused their attention heavily on Scaridae, thereby depleting the standing stock, which may have already been low in comparison to other islands in the region due to Rapa's subtropical location. Breeding rates may have been lower for the same reason. However such an explanation is very difficult to substantiate without further data on fish numbers, breeding rates and so on for the island. Environmental changes may also provide an explanation for the changes in relative abundance of taxa evident at Tangarutu, and the following chapter returns to this topic.

The other major temporal change that occurs in this assemblage is between the middle level and the upper level. Here, Serranidae increases from $6 \%$ to $17 \%$ of the assemblage and moves from sixth-ranked taxa in terms of relative abundance, to second in the bottom half of the level, although its numbers drop off again slightly in the upper half. The upper level also sees Pomacentridae enter the top-ranking taxa for the first time, comprising $8 \%$ of the assemblage in the upper half of the level, and Lethrinidae also increases in numbers. 
The data for the R1 area at Tangarutu are similar to those from the E1/E2 area in terms of taxa composition. There are, however, some differences in relative abundance. There is a general stratigraphic connection between the two areas (Chapter 3), but it is not certain that the levels at R1 occupy the same periods as those at E1/E2.

The lowest level in the R1 area does not contain sufficient fish bone to make any statements about it. In Level II, Muraenidae dominates, with Scaridae making a significant contribution also. This changes significantly in Level III, where Chaetodontidae numbers increase substantially, while Scaridae numbers drop. This level shows considerable similarity to the upper two-thirds of the middle level in the eastern area, again indicating a predominance of netting or basket trapping. Of particular note is the fact that the rapid decrease in the number of Scaridae is evident in both areas.

\section{Akatanui}

The assemblage from Akatanui 3 shows some interesting differences from those at Tangarutu. While three areas were excavated at Akatanui 3, only one of these provided sufficient fish bone to make any meaningful comment on fishing strategies. Radiocarbon dates suggest that occupation at this shelter began later than at Tangarutu, but that occupation at the two locations overlaps. Akatanui is located on the eastern, and windward, side of the island, and although the shelters investigated are located further into the bay than Tangarutu on the leeward side of the island, the differences in ecology and environment may be expected to have had some impact on fishing in terms of accessibility to some families of fish.

While the same species as in the Tangarutu assemblage are seen at Akatanui 3, there are differences in ranking and relative abundances. The most startling of these is the large proportion of Pomacentridae present, making up $25 \%$ of the assemblage and almost equal to the proportion of Scaridae. Pomacentridae is rarely identified in Pacific fish-bone assemblages, and when it is, it ranks very low. While this is probably due at least in part to the methodology used for identification, the large number present in this assemblage is surprising. It is interesting to note that Chaetodontidae ranks very low in the Akatanui 3 assemblage. The question of the significance of both Pomacentridae and Chaetodontidae in the Rapan assemblages is taken up below.

Eels continue to be important at Akatanui 3, as at Tangarutu, but in lower numbers. Labridae and Serranidae also contribute to the top-ranking families, with roughly the same numbers as Muraenidae and Congridae.

The differences seen between the Tangarutu assemblages and Akatanui 3 are probably related to ecology, perhaps due to the leeward/windward distinction, rather than a choice to focus on different fish at each site.

\section{Unusual taxa}

Returning to the large numbers of Chaetodontidae and Pomacentridae in the Rapan assemblages, ethnographic data suggest that these fish should also be present in other Pacific Island fish-bone assemblages, and that their absence in other assemblages is therefore due, at least in part, to methodological issues. Akimichi (1986), Goto (1986, 1990), Kirch and Dye (1979) and Masse (1986, 1989), in particular, note the presence of both these families in fish catches recorded ethnographically for Satawal, Hawaii, Niuatoputapu and Palau respectively. Ayres (1986) also reports Chaetodontidae and Pomacentridae as families known or suspected to have been exploited on Easter Island, and provides a schematic drawing showing the zones in which they were probably caught. Both Hawaii and Easter Island share similarities with Rapa in terms of environment and marine ecology, with the cooler climates of these islands inhibiting coral 
growth and their remoteness resulting in an impoverished range of marine taxa (Anderson 2001). The coastal characteristics of Easter Island are analogous to those of Rapa in terms of the lack of a fringing reef and the presence of deep embayments (Ayres 1986; Anderson 2001). Particularly for the small number of Pacific Island assemblages that have yielded Pomacentridae mouth parts, a reanalysis using the methodology used for Rapa may provide some very interesting results, given that not a single bone from the standard five paired mouth bones normally used in analyses of Pacific fish bone was identified in the Rapan assemblages.

The large number of marine eels present in the Rapan assemblages, particularly those from Tangarutu, is also somewhat anomalous. This is unlikely to be due to methodology, as MNIs for these were based on the five paired mouth parts for both Congridae and Muraenidae. Rather, it seems likely that the environmental conditions on Rapa resulted in eels being more easily accessible, or perhaps more plentiful, than those families usually more favoured by Polynesians.

\section{Fish size}

A final observation about the Rapan assemblages is the very small size of the remains. While no quantitative data on element size was collected (although it could be in another project on the bone assemblages), casual inspection suggests the bones are much smaller than is typical for tropical fish-bone assemblages. This is true for all families represented in the assemblage, although the occasional large example does exist. In this respect, while Pomacentridae and Chaetodontidae could possibly be considered of little economic importance in many fish catches due to their size, for Rapa they are probably within the average size of the catch, although, of course, this cannot be substantiated without quantitative data.

While Rapa may appear anomalous in terms of fish size, there are several other sites throughout the Pacific where the archaeological fish-bone remains have been particularly small, including Nan Madol, Leluh on Kosrae, Palau, and Cikobia in Fiji, and sites in New Caledonia and the Loyalty Islands (Davidson et al. 2002). Leach et al. (1996) proposed various explanations for the small size of the fish from Nan Madol: fishing was concentrated in areas where small fish congregated (i.e. the canals formed by the artificial islets that make up Nan Madol); the fish harvest was distributed according to rank (resulting in all the small-fish remains ending up in one area); the selection of small specimens for ritual purposes; ecological impact (i.e. decreasing size through time due to over-harvesting); the use of small mesh nets; and the use of fish poison. Some of these explanations may be applicable to Rapa, although others can be ruled out.

Fishing in confined areas where small fish congregated seems an unlikely explanation for Rapa, as areas such as those characteristic of Nan Madol were not present. It should be noted, however, that stone-walled fish weirs were used historically and can be seen in some of the bays around the island, especially in the main harbour. Over-harvesting also seems unlikely, given that Level I in Tangarutu is thought to represent initial, or very early occupation of the island (Kennett et al. 2006), and the fish remains are small throughout the entire span of occupation. Distribution of fish according to rank also seems unlikely, given that the fish bone from all excavated areas, in some cases several areas within one site, is equally small, and ritual uses can be ruled out for the same reason. Of the possibilities listed by Leach et al. (above), this leaves small meshed nets, the use of fish poison, and environmental constraints as the most likely explanations for the small size of fish remains from Rapa.

A case has already been made for the use of netting to account for many of the top-ranking fish families seen in the Rapan assemblages, and Masse (1986) discusses the use of fine-meshed nets (derek) for capturing Chaetodontidae in Palau. However, this does not account for the small 
size of the fish likely to have been caught using other methods, such as the Serranids and eels.

Davidson et al. (2002) propose an argument for fish poisoning at Nan Madol, but these waterways are especially slow moving. Poisoning is a possible explanation, although it was unknown ethnographically (Stokes n.d.). The presence of fish hooks at Tangarutu testifies to the use of angling, and the very small size of some of them suggests that quite small fish were being targeted by angling. It seems likely, therefore, that the small size of the fish in the Rapan assemblages is best attributed to environmental factors relating to climate and accessibility. The cooler waters surrounding Rapa might have resulted in slower growth rates and smaller mature sizes for families better suited to tropical waters. Alternatively, as even in modern times fishing is mostly confined to the calmer waters of the bays (Hanson 1970), larger-bodied offshore fish might have been caught rather seldom.

\section{Pacific comparisons}

How does the archaeological evidence of Rapan fishing compare with that from other islands in the Pacific? The analysis of archaeological fish bone from the Pacific has revealed an emphasis on inshore exploitation, focused mainly on the reef but also including the benthic zone, with the dominant families caught including Scaridae, Serranidae, Lethrinidae, Labridae, Diodontidae, Holocentridae, Acanthuridae, Balistidae, Carangidae and marine eels (Butler 1988, 1994; Masse 1989; Allen 1992, 2002; Nagaoka 1993; Anderson 1997; Walter 1998; Leach and Davidson 2000; Allen et al. 2001; Weisler 2001; Walter and Anderson 2002). Exceptions are known; some families that usually rank fairly low in assemblages dominate in a few cases, especially where offshore fishing is more prominent, or it has been focussed on one family (Butler 1994; Leach et al. 1997; Fraser 1988, 2001; Rolett 1998; Davidson et al. 1999; Leach and Davidson 2000; Walter and Anderson 2001). In terms of captured species, Pacific fish remains from archaeological sites generally represent a wide range of species drawn from a limited number of families.

In both the tropical Pacific and New Zealand selective predation of a particular family of fish is suggested (Leach and Boocock 1993; Anderson 1997 (but see Weisler et al. 1998); Leach et al. 1997; Fraser 1998, 2001; Walter and Anderson 2001). Scombridae (tuna) remains are generally scarce or absent in Pacific fish-bone assemblages, but it appears that tuna fishing was more common in some periods in the Marquesas and Society Islands during prehistory (Leach et al. 1997; Fraser 1998, 2001; Rolett 1998; Davidson et al. 1999; Leach and Davidson 2000). Walter and Anderson (2001) observed that Lethrinidae, a family of benthic-dwelling carnivores, provided the dominant catch at Emily Bay, Norfolk Island, suggesting that temperate waters resulted in a fishing strategy more akin to that of New Zealand than that of tropical Polynesia. In New Zealand, fish-bone analysis implies an emphasis on barracouta (Thyrsites atun) in the southern South Island, although there are exceptions, as at Kakanui. Whether these are formed by different targeting or different analytical methodology remains open to debate (Weisler et al. 1998; Anderson and Smith 1999; Weisler 1999).

The Pacific fishing industry, derived from the Lapita cultural complex (Walter 1989), displays a great deal of homogeneity across the region in terms of basic fishing strategies. But there are important differences at both the intra- and inter-island levels. Butler (1994) reviewed the evidence for Lapita fishing strategies and found that, contrary to earlier assertions, angling was used by the Lapita peoples, as evidenced by the presence of carnivorous fish remains at some sites. It was also found that eastern sites were dominated by herbivorous/omnivorous species, while sites in western Melanesia tended to contain more carnivorous fish, implying a regional difference in fishing strategies. 
While the strategies employed across the region are much the same, the species targeted show variations in relative abundance. Specialisations, such as in tuna fishing, are an extreme example of this. The tuna fishing industry seems to be an example of cultural choice, but in some sites the differences appear to be related to local ecology. Scaridae was a favoured fish family during prehistory, yet its remains are scarce in the fish-bone assemblages from Ma'uke and Mangaia. Walter (1998) attributes this to the inaccessibility of the outer reef face on these two islands, highlighting the need for a knowledge of local fishing grounds, ecology and accessibility when analysing fish remains.

While Rapa seems to fit the mould of an emphasis on inshore exploitation in general terms, it has already been noted that the Rapan assemblages differ on a number of points, specifically the high number of marine eels present, the presence of Chaetodontidae and Pomacentridae, and the small size of the fish. But are there other islands where a similar pattern can be seen?

Comparisons between assemblages are difficult due to differences in identification and quantification methodologies. Many early reports relied on a limited number of elements for identification, and few have used more than the standard five paired mouth bones. Furthermore, some researchers report only NISP values, while others give only MNI. NISP values may be inflated for some families due to the use of a wider range of elements for identification (e.g. Scaridae) or the use of elements for which each individual has multiple elements (e.g. Diodontidae). The present study is obviously skewed in comparison with others by the use of a wider range of elements for identification purposes. However, if these factors are taken into account, some observations are able to be made.

Eels are generally considered unusual in prehistoric middens, yet they show up in a number of middens throughout the region (e.g. Kirch and Yen 1982; Allen 1992; Nagaoka 1993; Leach et al. 1996; Walter 1998; Butler 2001; Walter and Anderson 2001; Davidson et al. 2002; Walter and Anderson 2002), although only occasionally in high-ranking positions. However, only on one other island is the dominance as clear as at Rapa, and that is on Easter Island, with the other dominant family in these sites being Labridae (Ayres 1986). The similarities between Rapa and Easter Island in terms of ecology and geomorphology have already been discussed, and it is not surprising to see similarities between the two in terms of fishing strategies. So, do the fish-bone assemblages from Rapa and Easter Island represent what could be considered a subtropical fishing strategy?

Only a small number of subtropical islands have been investigated archaeologically, and reports on fishing are pending for some. Norfolk Island displays a fishing strategy more like that of New Zealand, focusing on a single family (Walter and Anderson 2001) rather than the more generalised strategy common throughout the tropical zone. However, Norfolk is further outside the tropical zone than Rapa and Easter Island, and coral formation is extremely limited. Norfolk Island also lacks the bays characteristic of both Rapa and Easter Island, which no doubt affected accessibility to fishing grounds. This suggests that the pattern seen at Rapa and Easter Island is just one way in which prehistoric Polynesians adapted to subtropical islands, and that as in the tropical zone proper, local ecology played a large part in shaping fishing strategies.

The Rapan fish-bone assemblages show a strategy closely aligned to tropical Polynesia, with some interesting adaptations to local ecology and its constraints. A generalised strategy focused on several families is evident, dominated by inshore taxa. The large numbers of Pomacentridae and Chaetodontidae in the assemblages are at this stage unique to Rapa, but the use of more elements for the identification of assemblages from other localities should reveal whether or not this is an anomaly. In particular, it is interesting that the scarcity or absence of these families from archaeological assemblages in Hawaii and Easter Island has been queried, as both places have 
some similarities with Rapa in terms of coastal geomorphology and ecology. The dominance of marine eels, in particular Muraenidae, is paralleled in other parts of the Pacific, particularly in Easter Island. What at first appears to be a strange set of assemblages may yet turn out to be not so strange after all.

\section{References}

Akimichi, T. 1986. Conservation of the sea: Satawal, Micronesia. In: Anderson, A. (ed), Traditional Fishing in the Pacific. Pacific Anthropological Records 37:15-33.

Allen, M. 1992. Dynamic Landscapes and Human Subsistence: archaeological investigations on Aitutaki island, southern Cook Islands. PhD thesis, University of Washington.

Allen, M. 2002. Resolving long-term change in Polynesian marine fisheries. Asian Perspectives 41(2):195-212.

Allen, M, Ladefoged, T. and Wall, J. 2001. Traditional Rotuman fishing in temporal and regional context. International Journal of Osteoarchaeology 11:56-71.

Anderson, A.J. 1973. Archaeology and Behaviour: prehistoric subsistence behaviour at Black Rocks peninsula, Palliser Bay. MA thesis, Anthropology Department, University of Otago.

Anderson, A.J. 1979. Prehistoric exploitation of marine resources at Black Rocks Point, Palliser Bay. In: Leach, B.F and H.M. (eds), Prehistoric Man in Palliser Bay. National Museum of New Zealand Bulletin 21:49-63.

Anderson, A.J. 1986. Introduction. In: Anderson, A. (ed), Traditional Fishing in the Pacific. Pacific Anthropological Records 37:ix-xi.

Anderson, A.J. 1997. Uniformity and regional variation in marine fish catches from prehistoric New Zealand. Asian Perspectives 36(1):1-26.

Anderson, A.J. 2001. No meat on that beautiful shore: The prehistoric abandonment of subtropical Polynesian islands. International Journal of Osteoarchaeology 11:14-23.

Anderson, A.J. and Smith, I.W.G. 1999. Letter to the Editor. Archaeology in New Zealand 42:182-184.

Ayres, W.S. 1986. Easter Island subsistence. Journal de la Société des Ocieanistes 80:103-124.

Bilton, M. 2001. Taphonomic Bias in Pacific Ichthyoarchaeological Assemblages: A Marshall Islands Example. Unpublished MA thesis, Department of Anthropology, University of Otago.

Butler, V.L. 1988. Lapita fishing strategies: The faunal evidence. In: Kirch, P.V. and Hunt, T.L. (eds), The Archaeology of the Lapita Cultural Complex: A Critical Review. Thomas Burke Memorial Washington State Museum Research Report, No. 5, pp. 99-116, Seattle.

Butler, V.L. 1994. Fish feeding behaviour and fish capture: The case for variation in Lapita fishing strategies. Archaeology in Oceania 29:81-90.

Butler, V.L. 2001. Changing fish use on Mangaia, Southern Cook Islands: Resource depression and the prey choice model. International Journal of Osteoarchaeology 11:88-100.

Cannon, D.Y. 1987. Marine Fish Osteology: A Manual for Archaeologists. Simon Fraser University Publication 18, Department of Archaeology.

Davidson, J., Fraser, K., Leach, B.F. and Sinoto, Y.H. 1999. Prehistoric fishing at Hane, Ua Huka, Marquesas Islands, French Polynesia. New Zealand Journal of Archaeology 21:5-28.

Davidson, J., Leach, F. and Sand, C. 2002. Three thousand years of fishing in New Caledonia and the Loyalty Islands. In: Bedford, S., Sand, C. and Burley, D. (eds), Fifty Years in the Field: Essays in Honour and Celebration of Richard Shutler Jr's Archaeological Career. New Zealand Archaeological Association Monograph 25:153-164.

Fraser, K. 1988. Fishing for Tuna in Pacific Prehistory. Unpublished MA thesis, Department of Anthropology, University of Otago. 
Fraser, K. 2001. Variation in tuna fish catches in Pacific prehistory. International Journal of Osteoarchaeology 11:127-135.

Goto, A. 1986. Prehistoric Ecology and Economy of Fishing in Hawai'i: An Ethnoarchaeological Approach. Unpublished PhD thesis, University of Hawai' i.

Goto, A. 1990. Prehistoric Hawaiian fishing lore: An integrated approach. Man and Culture in Oceania 6:1-34.

Grayson, D.K. 1984. Quantitative Zooarchaeology: Topics in the Analysis of Archaeological Faunas. Academic Press, San Diego.

Hanson, F.A. 1970. Rapan Lifeways: Society and History on a Polynesian Island. Little, Brown and Company Ltd, Boston.

Kennett, D., Anderson, A., Prebble, M., Conte, E. and Southon, J. 2006. Prehistoric human impacts on Rapa, French Polynesia. Antiquity 80:340-354.

Kirch, P.V. and Dye, T. 1979. Ethnoarchaeology and the development of Polynesian fishing strategies. Journal of the Polynesian Society 88(1):53-76.

Kirch, P.V. and Yen, D.E. 1982. Tikopia: The prehistory and ecology of a Polynesian outlier. Bernice P. Bishop Museum Bulletin 238, Honolulu.

Leach, B.F. 1979. Excavations in the Washpool Valley, Palliser Bay. In: Leach, B.F. and H.M. (eds), Prehistoric Man in Palliser Bay. National Museum of New Zealand Bulletin 21:67-136.

Leach, B.F. 1986. A method for the analysis of Pacific island fish bone assemblages and an associated database management system. Journal of Archaeological Science 13:147-159.

Leach, B.F. and Boocock, A. 1993. Prehistoric Fish Catches in New Zealand. Oxford: British Archaeological Reports, International Series 584.

Leach, B.F., Davidson, J. and Athens, J.S. 1996. Mass harvesting of fish in the waterways on Nan Madol, Pohnpei, Micronesia. In: Davidson, J., Irwin, G., Leach, F., Pawley, A. and Brown, D. (eds), Oceanic Culture History: Essays in Honour of Roger Green, pp. 319-341. New Zealand Journal of Archaeology Special Publication, Wellington.

Leach, B.F., Davidson, J., Horwood, M. and Ottino, P. 1997. The fishermen of Anapua Rock Shelter, Ua Pou, Marquesas Islands. Asian Perspectives 36(1):51-66.

Leach, B.F. and Davidson, J. 2000. Fishing: A neglected aspect of Oceanic economy. In: Anderson, A. and Murray, T. (eds), Australian Archaeologist: collected papers in honour of Jim Allen, pp. 412-426. Coombs Academic Publishing, The Australian National University, Canberra.

Masse, W.B. 1986. A millennium of fishing in the Palau Islands, Micronesia. In: Anderson, A. (ed), Traditional Fishing in the Pacific: Ethnographical and Archaeological Papers from the 15th Pacific Science Congress. Pacific Anthropological Records, No. 37, pp. 85-119. Department of Anthropology, Bernice P. Bishop Museum, Honolulu.

Masse, W.B. 1989. The Archaeology and Ecology of Fishing in the Belau Islands. Unpublished PhD thesis, University of Southern Illinois.

Nagaoka, L. 1993. Faunal assemblages from the To'aga site. In: Kirch, P.V. and Hunt, T.L. (eds), The To'aga Site: Three Millennia of Polynesian Occupation in the Manu'a Islands, American Samoa. Contributions of the University of California Archaeological Research Facility No. 51, pp. 189-216. Berkley, California.

Rojo, A.L. 1991. A Dictionary of Evolutionary Fish Osteology. CRC Press, Boca Raton.

Rolett, B. 1998. Fishing strategies: Ethnographic observations and analysis of the excavated fish remains. In: Rolett, B. Hanamiai: Prehistoric Colonisation and Cultural Change in the Marquesas Islands (East Polynesia), vol. 81, pp. 118-146. Department of Anthropology and the Peabody Museum, Yale University, New Haven, Connecticut.

Stokes, John F.G. n.d. Ethnology of Rapa. Manuscript on file. Bernice P. Bishop Museum, Honolulu. Vogel, Y. 2005. Ika. Unpublished MA thesis, Department of Anthropology, University of Otago. Walter, R. 1998. Fish and fishing. In: Walter, R. (ed), Anai'o: The Archaeology of a Fourteenth Century 
Polynesian Community in the Cook Islands. New Zealand Archaeological Association Monograph 22, pp. 64-73.

Walter, R. 1989. Lapita fishing strategies: A review of the archaeological and linguistic evidence. Pacific Studies 13:127-149.

Walter, R. and Anderson, A. 2001. Fishbone from the Emily Bay settlement site, Norfolk Island. In: Anderson, A. and White, P. (eds), The Prehistoric Archaeology of Norfolk Island, Southwest Pacific. Records of the Australian Museum, Supplement 27, pp. 101-108. Australian Museum, Sydney.

Walter, R. and Anderson, A. 2002. Marine fishbone. In: Walter, R. and Anderson, A. (eds), The Archaeology of Niue Island, West Polynesia. Bishop Museum Bulletin in Anthropology 10, pp. 94-102. Bishop Museum Press, Honolulu.

Walter, R. and Weisler, M. 2002. Late prehistoric fishing adaptations at Kawakiu Nui, Molokải. Hawaiian Archaeology 8:42-61.

Walter, R., Weisler, M. and Smith, I. 1996. The Pacific fish bone reference collection at the University of Otago. Archaeology in New Zealand 39:200-212.

Weisler, M. 1993. The importance of fish otoliths in Pacific Island archaeofaunal analysis. New Zealand Journal of Archaeology 15:131-159.

Weisler, M. 1999. Letter to the Editor. Archaeology in New Zealand 42:184-186.

Weisler, M. 2001. On the Margins of Sustainability: Prehistoric Settlement of Utrok Atoll, Northern Marshall Islands. British Archaeological Reports International Series 967, Oxford.

Weisler, M., Lalas, C. and Rivett, P. 1998. New fish records from an Archaic midden, South Island. Archaeology in New Zealand 42:37-43.

Wheeler, A. and Jones, A.K.G. 1989. Fishes. Cambridge University Press, Cambridge. 